\title{
The second language interferes with picture naming in the first language: evidence for $L 2$ activation during L1 production
}

\section{Jana Klaus, Kristin Lemhöfer \& Herbert Schriefers}

To cite this article: Jana Klaus, Kristin Lemhöfer \& Herbert Schriefers (2018) The second language interferes with picture naming in the first language: evidence for L2 activation during L1 production, Language, Cognition and Neuroscience, 33:7, 867-877, DOI: 10.1080/23273798.2018.1430837

To link to this article: https://doi.org/10.1080/23273798.2018.1430837
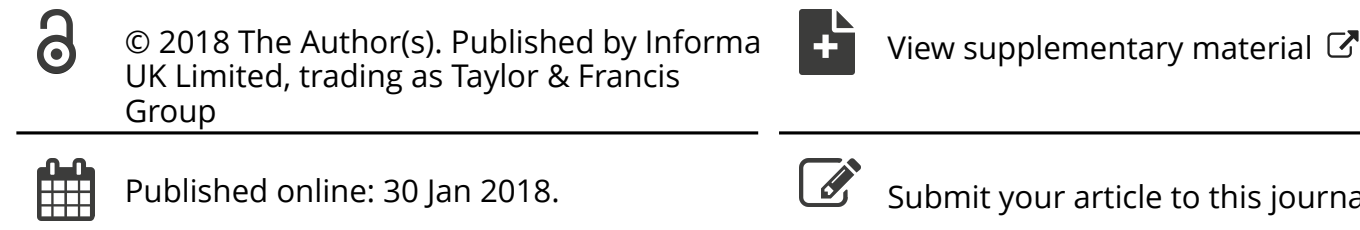
UK Limited, trading as Taylor \& Francis

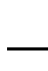

Џلll Article views: 639

View Crossmark data \lceil

Citing articles: 1 View citing articles $\square$ 


\title{
The second language interferes with picture naming in the first language: evidence for L2 activation during L1 production
}

\author{
Jana Klaus, Kristin Lemhöfer and Herbert Schriefers \\ Donders Centre for Brain, Cognition and Behavior, Radboud University, Nijmegen, The Netherlands
}

\begin{abstract}
Previous research has shown that when speakers produce words in their second language (L2), they also activate the phonological form of the translation of the word in their first language (L1). Here we investigated whether this holds in the opposite direction, i.e. when participants speak in exclusively in their L1. In a picture-word interference task, speakers named pictures in their L1 Dutch ("mes" [knife]) while ignoring L2 English auditory distractors phonologically related to the English translation of the target ("knight") or unrelated ("plane"). Naming latencies were longer in the related compared to the unrelated condition, suggesting that the L2 translations were activated up to the phonological level. However, this pattern was only obtained when speakers were addressed in the target language (Dutch) throughout the experiment. Moreover, the size of this effect did not depend on individual L2 proficiency. We conclude that co-activation of two languages is not restricted to the dominant language.
\end{abstract}

\section{ARTICLE HISTORY}

Received 4 July 2017

Accepted 22 December 2017

\section{KEYWORDS}

Bilingual language

production; language co-

activation; picture-word

interference; phono-

translation effect

\section{Introduction}

Bilingual language production represents a particularly complicated case of the already complex process of language production. Unlike in monolingual speech production, speakers do not only have to select a to-beexpressed concept and assign it the appropriate lexical-semantic and phonological attributes, they also have to select the currently appropriate language. In general, it is assumed that the activation flow from the conceptual to the lexical system is not language-specific, i.e. both languages are activated and spread information to the lexical nodes regardless of the target language (e.g. Costa, 2004; Costa \& Caramazza, 1999; De Bot, 1992; Green, 1998; Hermans, Bongaerts, De Bot, \& Schreuder, 1998). However, it is still debated whether lexical selection, too, is non-specific with respect to language. Some studies suggest that lexical entries / representations from both languages compete for selection, and that to resolve this competition, the non-target language is actively inhibited (Abutalebi \& Green, 2007; Costa, Colomé, Gómez, \& Sebastián-Gallés, 2003; Green, 1998; Hermans et al., 1998; Jacobs, Fricke, \& Kroll, 2016; Kroll, Bobb, Misra, \& Guo, 2008; Misra, Guo, Bobb, \& Kroll, 2012; Spalek, Hoshino, Wu, Damian, \& Thierry, 2014), while others advocate language-specific lexical selection in which no competition for selection arises between two languages (Colomé, 2001; Costa \& Caramazza, 1999; Costa, Miozzo, \& Caramazza, 1999). More recently, it has been proposed that lexical selection in bilingual language production may be thought of as a dynamic process, in which language-selectivity can be achieved temporarily depending on a number of variables both specific to the speakers involved (e.g. proficiency, language dominance) and the experimental parameters used (e.g. proportion of experimental and filler trials; Boukadi, Davies, \& Wilson, 2015; Costa et al., 2003; Hermans, Ormel, van Besselaar, \& van Hell, 2011; Kroll, Bobb, \& Wodniecka, 2006). In the present study, we focus on the question how language dominance may affect language-(non)specificity in lexical selection up to the phonological level. More specifically, we investigate whether a less dominant language, i.e. the L2 which is used substantially less than the L1 in daily life, still reaches activation up to the phonological level during production in the $\mathrm{L} 1$.

In word recognition studies, effects of the L2 on L1 processing have indeed been reported, but they tend to be much smaller than those obtained in L2 processing (de Groot, Borgwaldt, Bos, \& van den Eijnden, 2002; Gollan, Forster, \& Frost, 1997). In language production, however, this question, has only been investigated for the opposite direction so far, i.e. co-activation of (the 
dominant) L1 during production in (the non-dominant) L2. Before presenting our experiments, we will therefore summarise previous studies that explicitly investigated cross-language effects in this latter direction, i.e. co-activation of L1 translations in L2 production making use of the so-called phono-translation effect.

\section{Cross-Language activation in bilingual word production}

In their seminal study, Hermans et al. (1998) showed that when speakers have to name pictures in their L2 (in their case English), the L1 (in their case Dutch) translation of the target word is also activated up to the phonological level. In two picture-word interference experiments, participants were asked to name pictures of simple objects in their L2 (e.g. "mountain") while ignoring auditory distractor words. The relation of the distractor word to the target word, as well as its onset relative to the presentation of the picture (i.e. the SOA) were systematically varied. When the distractor words were English words (i.e. from the target language), naming latencies were longer if the distractor word began with the same phonemes as the L1 translation of the target word (e.g. "bench" for "berg", the Dutch translation of "mountain") compared to an unrelated distractor (e.g. "present"). However, this effect was only reliable in the by-participant analysis, and only if the distractor word appeared at the same time as the picture (SOA $0 \mathrm{~ms}$, as opposed to SOAs $-300,-150$, and $150 \mathrm{~ms}$ ). When Dutch distractors were used instead of English ones, the same manipulation (i.e. a related distractor like "berm" [verge] as opposed to an unrelated distractor like "kaars" [candle]) yielded a descriptively somewhat larger and overall statistically reliable interference effect. This phenomenon, which was coined phono-translation effect, was interpreted as evidence for non-language specific lexical competition during bilingual language production, as the non-target language translation of the to-be-produced word was activated up to the phonological level, and interfered with the production of the L2 target word.

Costa et al. (2003) replicated the phono-translation effect in highly proficient bilinguals. Native Spanish speakers named pictures in their L2 (Catalan) while ignoring Spanish auditory distractor words that were phonologically related or unrelated to the L1 (Spanish) translation of the target word. In Experiment 1, an interference effect from translation-related distractors comparable in size to the one reported by Hermans et al. (1998) was found at SOAs $-150,0$, and $150 \mathrm{~ms}$. To decrease the likelihood that participants strategically used the distractors during naming, the proportion of related distractors was reduced in Experiment
2. Following this adjustment, an interference effect from translation-related distractors only showed up at SOA 150 ms. Costa et al. (2003) concluded that crosslanguage interference occurs even in highly proficient bilinguals.

Boukadi et al. (2015) investigated the phono-translation effect between two typologically more distant languages (i.e. French and Tunisian Arabic) in moderately proficient bilinguals. Like Hermans et al. (1998), they measured the amount of phono-translation interference, but using distractor words from the L2 (Experiment 1) or the L1 (Experiment 2) in an L2 picture naming task. In Experiment 1, participants were asked to name pictures in their L2 (French) while ignoring auditory distractor words in their L2 which were phonologically related or unrelated to the L1 translation of the target word. For example, when producing "bougie" (candle), which is /Jamfa/ in Arabic, the related distractor would be "chapeau" (/ $\mathrm{apo} /$, hat) and the unrelated distractor would be "feuille" (/fœj/, leaf). The authors found no difference between these conditions at any of the three SOAs tested $(-150,0,150 \mathrm{~ms})$, implying a strictly language-specific lexical selection process. By contrast, when the distractors came from the L1 (e.g. / Jabka/ [net] as a related distractor and /warqa/ [leaf] as an unrelated distractor), a phono-translation effect was indeed observed. The authors concluded that in a "bilingual experimental mode" (i.e. when both the L1 and the L2 are activated by the experimental paradigm), speakers have a harder time to resolve lexical competition as competitors from both languages are activated in parallel.

Costa, Albareda, and Santesteban (2008) investigated the phono-translation effect in a Stroop task. Highly proficient Spanish-Catalan (Experiment 1) and CatalanSpanish speakers (Experiment 2) named the print colour of a visually presented word in their L2, while the word itself was an L1 word with varying relations to the target utterance (e.g. when a blue word had to be named as "blau" [Catalan for blue], the word itself would be phonologically related to the L1 translation ["azucar", which is related to "azul", Spanish for blue] or unrelated ["corona", Spanish for crown]). With a small response set (eight possible utterances, including four filler items), naming latencies did not differ between these two conditions (Experiment 1). After slightly increasing the response set (10 possible utterances, including five filler items), related distractors sped up naming latencies compared to the unrelated condition, that is, the phono-translation effect became facilitatory as opposed to inhibitory as observed in previous picture naming studies. The authors argued that the phono-translation effect might be a compound of semantic facilitation and lexical inhibition, with the 
former outweighing the latter in situations of small response sets. Note, however, that this study, like the studies mentioned above, was only conducted in an L2 naming context, allowing no inferences as to what extent the L2 is activated during L1 naming.

In sum, previous studies investigating the phonotranslation effect have shown that when speaking in one's L2, the L1 translation of the target word can be activated up to the phonological level. This effect seems to be relatively independent of L2 proficiency, but does depend on the concurrent, externally provided activation of the L1, as well as the experimental paradigm used. These results, overall, support a lexical selection process which, globally, is language non-specific, but can be language-specific in special situations (e.g. when the L1 is not used throughout the experiment, as in Boukadi et al., 2015, Experiment 1; Kroll et al., 2006). However, this particular cross-language activation has until now only been investigated for one direction, i.e. for the activation of the dominant native language while speaking in one's L2. It is thus possible that language dominance may indeed be a moderating factor, and that speaking in one's L1 is less susceptible to interference from the L2. In other words, the activation flow from the L2 to the L1 may potentially be much weaker.

Costa et al. (1999) tested simultaneous CatalanSpanish bilinguals in Catalan picture naming with a number of different distractor conditions. Spanish distractors were translations of Catalan words phonologically related to the Catalan target word. The authors found no effect compared to unrelated distractors, arguing against between-language phonological activation through translations. However, as pointed out by Hermans (2004), in contrast to between-language identity effects, the translation-mediated conditions used distractor words that were not part of the response set, which might have impeded their activation. With distractor words being part of the response set, Hermans (2004) indeed showed a reliable phono-translation effect, but only during L2 as opposed to L1 naming.

Further evidence pointing towards weaker activation from L2 to L1 comes from studies on the production of cognates (i.e. words which have a similar word form in L1 and L2). Costa, Caramazza, and Sebastián-Gallés (2000) and Starreveld, de Groot, Rossmark, and van Hell (2014) reported a cognate effect (i.e. faster naming latencies in the production of cognates as opposed to non-cognates) in picture naming which was substantially smaller in L1 naming than in L2 naming (cf. Strijkers, Costa, \& Thierry, 2010, who obtained comparable behavioural and electrophysiological effects in L1 and L2 cognate naming). However, cognates constitute a very specific subset of lexical entries in the bilingual case and only capture parts of the issues related to crosslanguage co-activation, in that they are by definition target-related (i.e. they always share a phonological overlap in L1 and L2). The current study thus extends the scope of previous cognate studies by investigating L2 co-activation during L1 production when exclusively naming non-cognates.

In the current study, we investigated whether the L2 translation of a target object is active during L1 production using the phono-translation paradigm. This will clarify whether language dominance is a factor determining the occurrence of cross-language competition during lexical selection. If an interference effect from L2 translation distractors is found in L1 production as well, this would add further support to the notion that lexical selection in bilingual language production is not language-specific. By contrast, if no such effect is obtained, one could assume that bilingual lexical selection is not language-specific only in one direction, i.e. in the case when the more dominant language cannot be suppressed, while activation from L2 to L1 can indeed be muted leading to language-specific lexical selection in L1 production.

\section{Experiment 1}

In Experiment 1, we tested whether the L2 (English) translations of to-be-produced L1 (Dutch) words are activated up to the phonological level. We employed a "reversed" variant of the phono-translation paradigm, that is, speakers named pictures in their L1 while ignoring auditory L2 distractor words phonologically related or unrelated to the L2 translation of the target word (i.e. phono-translation condition). We added an additional cross-language phonological condition, in which the related distractor shared the onset with the target word (e.g. "labour" for the target word "lepel" [spoon]). On the one hand, this reduced the percentage of related phono-translation distractors (see also Costa et al., 2003). On the other hand, we reasoned that distractors phonologically related to the target should cause phonological facilitation due to the segmental overlap between distractor and target word (Damian \& Martin, 1999; Schriefers, Meyer, \& Levelt, 1990) independent of the distractor language (see also Costa et al., 1999, Experiment 6, for evidence from SpanishCatalan speakers). That is, phonological facilitation should arise regardless of lexical competition from between-language representations. Finally, we tested all distractor conditions at two SOAs ( -150 and $0 \mathrm{~ms})$ because these SOAs have been shown to reveal a phono-translation effect in the L2-L1 direction (Costa et al., 1999; Hermans et al., 1998). 


\section{Methods}

\section{Participants}

Twenty-four students from the Radboud University Nijmegen (22 female, mean age: 21.8 years, $S D=2.3$ ) with normal hearing and normal or corrected-tonormal vision participated in exchange for course credit or monetary reimbursement. All participants were native Dutch speakers and raised monolingually. One participant was replaced because she was not able to name more than $50 \%$ of the items in English (see Procedure below). The 24 participants included in the analysis had mostly acquired English in high school and had had experience with English for, on average, 10.1 years $(S D=2.4)$.

\section{Materials}

Picture-word interference task. Twenty-eight line drawings depicting objects with mono- or disyllabic Dutch names which were not Dutch-English cognates were chosen as picture stimuli. They were presented in black and white at the centre of the screen, filling an imaginary square of $300 \times 300$ pixels. For each target, a phonotranslation distractor and a phonological distractor were created by selecting English words that shared the first two to three phonemes of either the English translation (e.g. "knight" for the target mes [knife]) or the Dutch word (e.g. "mesh" for mes [knife]) of the target. All distractors had the same stress pattern as the target word, and there were no semantic or associative relations between the target word and the respective distractors. Furthermore, log frequencies between the target words and the distractor words (derived from SUBTLEX; Brysbaert \& New, 2009; Keuleers, Brysbaert, \& New, 2010) did not differ ( $p s>.125)$. For the phonotranslation condition, all distractors had the same number of syllables as the English translation. For the cross-language phonological condition, we kept the number of syllables identical to the Dutch target word. Unrelated conditions were created by reassigning the distractors to other targets (see Appendix A for a list of the materials). Four more pictures and accompanying unrelated distractor words were selected for use in practice and warm-up trials.

The auditory distractors were created using the textto-speech application T2S, which uses the Google Textto-Speech Engine developed for Android (https://play. google.com/store/apps/details?id=hesoft.T2S). We chose a female English speaker with an American accent because we reasoned that Dutch speakers would be most accustomed to this accent from the media.
Proficiency measures. To obtain an indication of individual proficiency in English, we administered four additional tests: (1) a questionnaire requesting the participants to write down the English names of all the pictures used throughout the experiment, which allowed us to individually assess which of the L2 translations were known by the participants; (2) a multiple-choice grammar test (adapted from http://www.transparent. com/learn-english/proficiency-test.html), which required the completion of ten sentences with the correct grammatical form; (3) a multiple-choice reading comprehension test derived from the same source, which required answering questions about short paragraphs of text; and (4) the LexTALE (Lemhöfer \& Broersma, 2012) to estimate vocabulary size. Additionally, we administered a language background questionnaire which collected self-reported information on the daily use of English, self-ratings with respect to reading, listening, writing, and speaking proficiency, and the degree of immersion (see Appendix $C$ for a summary of the results across experiments).

\section{Design}

The design contained the factors relatedness (phonologically related vs. unrelated), and SOA (-150 ms vs. $0 \mathrm{~ms}$ ), examined separately for the phono-translation and the cross-language phonological condition. All factors were tested within participants and items. Each target was presented in each of the eight experimental conditions once, resulting in 224 experimental trials per participant. SOA was blocked, with the order counterbalanced across participants. Within each SOA block, the order of experimental conditions was counterbalanced using a sequentially balanced Latin square procedure. Pseudorandomised experimental lists were created based on the following restrictions: (a) repetition of a target was separated by at least eight intervening trials; (b) repetition of a distractor word was separated by at least five intervening trials; (c) no more than three trials from the same distractor condition (i.e. referring to distractor reference and relatedness) followed each other; (d) targets from the same semantic category were separated by at least three intervening trials; (e) targets with the same phonological onset were separated by at least two intervening trials.

\section{Apparatus}

The pictures were presented on a BenQ XL2420T monitor as black line drawings on a white background. Presentation of the pictures and the auditory distractor words and collection of the naming latencies was controlled by Presentation software (Version 18.1, Neurobehavioral 
Systems, Inc., Berkeley, CA, www.neurobs.com). Auditory distractors were presented with Sennheiser headphones, and naming latencies were measured to the closest millisecond with a voice key connected to the experimenter computer (Dell Precision T3610).

\section{Procedure}

Participants were tested individually in a soundproof booth separated from the experimenter. Throughout the experiment, participants were addressed in Dutch. After giving informed consent, a familiarisation block was administered in which all items were presented on the screen and participants were asked to name them in their L1 (Dutch) spontaneously. Immediately after each picture was named, the correct Dutch target noun was presented below the picture and participants were asked to use only these nouns throughout the experiment. In a practice block consisting of 12 trials, the naming task was combined with the auditory distractor presentation. Participants were asked to continue naming the pictures as fast as possible and to ignore the distractors. This practice block was followed by two experimental blocks (SOA -150 and $0 \mathrm{~ms}$ ) consisting of 112 trials each. After the naming task, the proficiency tests were administered. The language background questionnaire, item questionnaire, and reading and grammar test were presented in pencil-and-paper form. The LexTALE was administered as a computer version. An experimental session lasted about $45 \mathrm{~min}$.

A trial of the naming task was structured as follows. After presentation of a fixation cross for $250 \mathrm{~ms}$ and a blank screen for $250 \mathrm{~ms}$, the target picture appeared at the centre of the screen for a maximum of $1,000 \mathrm{~ms}$ or until the voice-key had registered a response. The distractor was presented at the same time as the picture, or $150 \mathrm{~ms}$ prior to that, depending on SOA. Participants

Table 1. Mean naming latencies in $\mathrm{ms}$ and error rates in percent of Experiment 1, broken down by SOA and distractor condition.

\begin{tabular}{|c|c|c|c|c|}
\hline & \multicolumn{2}{|c|}{$\mathrm{SOA}-150 \mathrm{~ms}$} & \multicolumn{2}{|c|}{$\mathrm{SOA} 0 \mathrm{~ms}$} \\
\hline & $\begin{array}{c}\text { RT in } \\
\mathrm{ms}\end{array}$ & $\begin{array}{c}\text { errors in } \\
\%\end{array}$ & $\begin{array}{l}\text { RT in } \\
\text { ms }\end{array}$ & $\begin{array}{c}\text { errors in } \\
\%\end{array}$ \\
\hline $\begin{array}{l}\text { translation- } \\
\text { related }\end{array}$ & $\begin{array}{l}747 \\
(22)\end{array}$ & $\begin{array}{c}2.5 \\
(0.8)\end{array}$ & $\begin{array}{l}761 \\
(25)\end{array}$ & $\begin{array}{r}2.8 \\
(0.8)\end{array}$ \\
\hline translation- & 706 & 1.0 & 741 & $\begin{array}{r}1.8 \\
(05)\end{array}$ \\
\hline unrelated & (15) & $(0.3)$ & (18) & $(0.5)$ \\
\hline difference & 42 & 1.6 & 23 & 1.0 \\
\hline cross-language & 711 & 2.2 & 729 & 2.1 \\
\hline $\begin{array}{l}\text { phonologically } \\
\text { related }\end{array}$ & (18) & $(0.7)$ & (21) & $(0.6)$ \\
\hline $\begin{array}{l}\text { cross-language } \\
\text { phonologically } \\
\text { unrelated }\end{array}$ & $\begin{array}{l}715 \\
(15)\end{array}$ & $\begin{array}{c}1.9 \\
(0.5)\end{array}$ & $\begin{array}{l}739 \\
(19)\end{array}$ & $\begin{array}{r}2.2 \\
(0.6)\end{array}$ \\
\hline difference & -4 & 0.3 & -10 & -0.1 \\
\hline
\end{tabular}

Note. Difference $=$ related - unrelated in ms. Positive difference scores reflect interference from related distractors, and negative scores reflect facilitation from related distractors. Standard errors of the mean are given in brackets. had a maximum of $3000 \mathrm{~ms}$ to respond. After the presentation of a blank screen for $250 \mathrm{~ms}$, the next trial was initiated.

\section{Results and discussion}

Separate analyses were performed for distractors that were related or unrelated to the translation of the target word (phono-translation condition) and for distractors that were related or unrelated to the Dutch target word (cross-language phonological condition). For the phono-translation condition, items that were not named correctly in English (in the proficiency test administered after the experiment) by at least $80 \%$ of the participants were removed ( 8 items; 768 observations; $14.3 \%)$. We did so to reduce overall noise in the data and because there is no reason to expect a reliable phono-translation effect if the intended English translation is not familiar to the participants. Note that for the cross-language phonological contrast, however, all items were used, because the distractor manipulation did not depend on whether participants knew the English translation of the target or not. The remaining dataset included 4608 observations. From this dataset, trials that could not be named in English by the respective participant were removed from the naming latency and error analyses for the phono-translation condition on an individual basis (64 observations; $1.4 \%$ ). Responses shorter than $200 \mathrm{~ms}$ or longer than $2000 \mathrm{~ms}$ were classified as technical errors and removed from the analyses without coding an error (64 observations; 1.4\%). Observations were coded as erroneous online by the experimenter and removed from the naming latency analysis whenever a picture had been responded to with a word other than the target word, no response had been given, a response was repaired, or a response was preceded by a non-speech sound (112 observations; 2.4\%). Observations deviating from a participant's and an item's median by more than two standard deviations were regarded as outliers and removed (124 observations; $2.6 \%)$.

Statistical analyses were computed with mixed-effects models using the Ime4 package (Version 1.1.10; Bates, Mächler, Bolker, \& Walker, 2015) in R (Version 3.2.4; R Core Team, 2017). Associated $p$ values were estimated using the ImerTest package (Version 2.0.33; Kuznetsova, Bruckhoff, \& Christensen, 2016). The factors relatedness (phonologically related vs. unrelated) and SOA $(-150 \mathrm{~ms}$ vs. $0 \mathrm{~ms})$ were contrast-coded and included as fixed effects in the models. Participants and items were included as random effects (Baayen, Davidson, \& Bates, 2008). Additionally, individual variability in the distractor effect was modelled by including random by- 
participant and by-item slopes for the relatedness factor. Error rates were analyzed using mixed logit regression (Jaeger, 2008). Table 1 displays mean naming latencies and error rates broken down by distractor reference (phono-translation vs. cross-language), relatedness, and SOA, averaged across participants.

\section{Distractor effects in naming task}

In the phono-translation condition, related distractors increased naming latencies compared to the unrelated condition, although this effect was only marginally significant $(\beta=15.82, S E=8.18, t=1.93, p=.064)$. Naming latencies were faster in the early SOA $(\beta=-12.73, S E=$ $3.02, t=-4.22, p<.001)$. There was a significant interaction of relatedness and SOA $(\beta=6.55, S E=3.02, t=$ $2.17, p=.030$ ), indicating that the interference effect from related distractors was only reliable at SOA $-150 \mathrm{~ms}(\beta=23.06, S E=7.27, t=3.17, p=.004)$, but not at SOA $0 \mathrm{~ms}(\beta=9.15, S E=9.39, t=0.97, p=.341)$. There were no significant effects in the analysis of error rates ( $p s>.256$ ).

In the cross-language phonological condition, there was only a main effect of SOA in the naming latency analysis, indicating shorter naming latencies at SOA $-150 \mathrm{~ms}$ than at SOA $0 \mathrm{~ms}(\beta=-10.37, S E=2.11, t=$ $-4.91, p<.001)$. None of the other effects were significant (for RT, all ps > .437; for error rates, all ps > .684).

\section{Influence of proficiency}

The upper part of Table 2 reports results from the proficiency tests administered after the naming task. To investigate whether the phono-translation effect was modulated by individual L2 proficiency, we calculated Pearson correlations between all proficiency scores and the size of the phono-translation effect. These correlations do not provide any evidence for a relationship between any of the proficiency measures and the size of the phono-translation effect (all $|r| s \leq .27$, uncorrected $p>.05$ ). Likewise, including the proficiency measures in

Table 2. Mean, standard deviation, and range for all proficiency measures, reported separately by experiment.

\begin{tabular}{lcrrrr}
\hline & & item score & grammar & reading & LexTALE \\
\hline Experiment 1 & $M$ & 86.61 & 77.78 & 94.58 & 76.08 \\
& $S D$ & 12.69 & 8.03 & 7.21 & 9.60 \\
& $\min$ & 53.57 & 60.00 & 80.00 & 58.00 \\
& $\max$ & 100.00 & 93.33 & 100.00 & 92.00 \\
Experiment 2 & $M$ & 86.31 & 79.17 & 95.00 & 76.63 \\
& $S D$ & 11.66 & 6.31 & 9.33 & 12.26 \\
& $\min$ & 60.71 & 66.67 & 60.00 & 53.00 \\
& $\max$ & 100.00 & 86.67 & 100.00 & 98.00 \\
Experiment 3 & $M$ & 93.23 & 76.67 & 91.67 & 76.33 \\
& $S D$ & 7.46 & 9.83 & 10.07 & 10.88 \\
& $\min$ & 70.83 & 60.00 & 70.00 & 57.00 \\
& $\max$ & 100.00 & 93.33 & 100.00 & 97.00 \\
\hline
\end{tabular}

the linear mixed-effects model did not yield any significant main effects or interactions with relatedness ( $p$ s $>$.407).

In sum, Experiment 1 showed that the $\mathrm{L} 2$ translations of to-be-produced L1 objects are activated up to the phonological level, regardless of the L2 proficiency level. This provides initial evidence that the phono-translation effect is in fact not a unidirectional phenomenon, but that the less dominant L2 also competes for lexical selection in L1 production (at least in a situation where the distractors are L2 words).

In contrast, the cross-language phonological condition did not yield the expected facilitation effect, which is at odds with the finding reported by Costa et al. (1999, Experiment 6) for Spanish-Catalan speakers. Importantly, however, in their study, distractors were presented visually, as opposed to auditorily in the current study. Thus, it is possible that the facilitating effect of L1-related L2 distractors was at least partly caused by facilitation due to the graphemic overlap between target and distractor word. More relevant for the present situation are findings from studies on cross-language phonological priming in spoken word recognition. Evidence from such word recognition studies suggests that highly proficient participants can differentiate categorically between the different phonological sets of the two languages, sometimes to the extent that any potential phonological cross-language effects are eliminated. Pallier, Colomé, and SebastiánGallés (2001) showed that in an auditory repetition priming experiment, one of the participant groups (highly proficient Catalan-Spanish bilinguals) showed no repetition priming effect when two phonologically minimally different words were presented (e.g. Catalan "pere" and Spanish "pera") showing that phonological priming in this case did not work across two languages. The authors interpreted this as evidence that lexical-phonological representations of L1 and L2 differ, and more importantly for the present question, that phonological priming/facilitation is not necessarily obtained between languages. Furthermore, studies on bilingual word recognition and production have shown that cross-language effects of orthographic neighbours are difficult to obtain (de Groot et al., 2002; Lemhöfer, Spalek, \& Schriefers, 2008), a phenomenon which even holds for cross-language homophones (Haigh \& Jared, 2007). Based on these findings, we assume that presentation of a to-be-named picture initially activates both the L1 (Dutch) and L2 (English) word of the target. Additionally, Dutch phonological neighbours of the Dutch target name as well as English phonological neighbours of the English word are activated, but not English phonological neighbours 
of the Dutch word or Dutch phonological neighbours of the English word.

To keep all experiments reported here comparable, we nevertheless decided to include this cross-language phonological condition in Experiments 2 and 3. To anticipate, none of the experiments reported here found an effect of cross-language phonologically related distractors.

\section{Experiment 2}

In Experiment 2, we tested whether boosting the activation of the $L 2$ could increase the competition between the two languages. The experiment was completely identical to the previous one, with the only difference that the participants were addressed in English (i.e. the L2) throughout the entire experiment, as opposed to Dutch in Experiment 1. ${ }^{1}$ Boukadi et al. (2015) reported evidence that additional external activation of the nontarget language (in their case, by presenting the distractors in the non-target language, L1), may increase its lexical activation throughout naming in L2. Experiment 2 was thus a test if that also holds in the opposite direction. If so, we would expect a larger phono-translation effect compared to Experiment 1, potentially across both SOAs tested.

\section{Method}

\section{Participants}

Twenty-four students from the Radboud University Nijmegen ( 20 female, mean age: 22.2 years, $S D=2.0$ ) with normal hearing and normal or corrected-to-normal vision participated in exchange for course credit or monetary reimbursement. As in Experiment 1, all participants

Table 3. Mean naming latencies in ms and error rates in percent of Experiment 2, broken down by SOA and distractor condition.

\begin{tabular}{|c|c|c|c|c|}
\hline & \multicolumn{2}{|c|}{ SOA $-150 \mathrm{~ms}$} & \multicolumn{2}{|c|}{$\mathrm{SOA} 0 \mathrm{~ms}$} \\
\hline & $\begin{array}{c}\text { RT in } \\
\text { ms }\end{array}$ & $\begin{array}{c}\text { errors in } \\
\%\end{array}$ & $\begin{array}{c}\mathrm{RT} \text { in } \\
\mathrm{ms}\end{array}$ & errors in \% \\
\hline $\begin{array}{l}\text { translation- } \\
\text { related }\end{array}$ & $\begin{array}{l}712 \\
(17)\end{array}$ & $\begin{array}{c}2.4 \\
(0.5)\end{array}$ & $\begin{array}{l}713 \\
(15)\end{array}$ & $4.2(1.0)$ \\
\hline translation- & 700 & 2.1 & 700 & 2.7 \\
\hline unrelated & (15) & $(0.6)$ & (14) & $(0.7)$ \\
\hline difference & 12 & 0.3 & 13 & 1.5 \\
\hline cross-language & 692 & 3.6 & 692 & 1.9 \\
\hline $\begin{array}{l}\text { phonologically } \\
\text { related }\end{array}$ & (15) & $(0.7)$ & (18) & $(0.7)$ \\
\hline $\begin{array}{l}\text { cross-language } \\
\text { phonologically } \\
\text { unrelated }\end{array}$ & $\begin{array}{l}699 \\
(13)\end{array}$ & $\begin{array}{c}3.0 \\
(0.8)\end{array}$ & $\begin{array}{l}712 \\
(12)\end{array}$ & $\begin{array}{l}3.0 \\
(1.0)\end{array}$ \\
\hline difference & -7 & 0.8 & -20 & -1.1 \\
\hline
\end{tabular}

Note. Difference $=$ related - unrelated in ms. Positive difference scores reflect interference from related distractors, and negative scores reflect facilitation from related distractors. Standard errors of the mean are given in brackets. Distractor effects in naming task were native Dutch speakers and raised monolingually, with an average of 8.9 years of learning English $(S D=2.6)$.

Materials, design, apparatus, \& procedure

Experiment 2 was identical to Experiment 1, with the only difference that participants were addressed in English throughout the experiment by the experimenter. The written instructions, however, were still presented in Dutch.

\section{Results and discussion}

The data were analyzed as in Experiment 1. For the phono-translation condition, items that were not named correctly in English (in the proficiency test administered after the experiment) by at least $80 \%$ of the participants were removed (8 items; 768 observations; $14.3 \%)$. Additionally, 72 trials (1.6\%) in which the English translation could not be named by an individual participant were removed from the phono-translation analyses for this participant without coding an error. 53 trials (1.2\%) with latencies shorter than $200 \mathrm{~ms}$ or longer than $2000 \mathrm{~ms}$ were coded as technical errors and removed. 153 observations (3.3\%) were marked as erroneous responses and entered into the error analyses. Finally, 143 observations (3.1\%) were identified as outliers and removed from the analysis. Table 3 displays mean naming latencies and error rates broken down by distractor reference (phono-translation vs. phonological) and SOA, averaged across participants.

\section{Distractor effects in naming task}

For the phono-translation condition, there were no significant effects in the analysis of naming latencies ( $p$ s $>$.299). In the analysis of error rates, there was only a marginally significant main effect of SOA $(\beta=-0.23$, SE $=0.12, z=-1.83, p=.067)$, indicating higher error rates at SOA $0 \mathrm{~ms}$. None of the other effects were significant ( $p s>$.443).

For the cross-language phonological condition, there were no significant effects in the analysis of naming latencies ( $p s>.097$ ) or error rates ( $p s>.185$ ).

\section{Influence of proficiency}

The middle layer of Table 2 displays the results from the proficiency measures collected in Experiment 2. Crucially, none of these values significantly differed from those obtained for the sample of Experiment 1 (all ps > .509), suggesting that we tested groups of comparable L2 proficiency. None of the proficiency measures correlated with the size of the distractor effect in the phono-translation condition (all $|r| s \leq .27$, uncorrected $p>.05$ ). Again, adding the proficiency measures to the linear mixed- 
effects models did not yield any significant effects ( $p$ s $>$.324).

In sum, in Experiment 2 we found no evidence that $L 2$ target translations were activated when participants named pictures in their L1. The only difference between the two experiments was the language in which the participants were addressed. Thus, boosting the activation of the non-target language resulted in the disappearance of the phono-translation effect observed in Experiment 1. We will return to this finding in the General Discussion.

\section{Experiment 3}

So far we showed that L2 translations compete for lexical selection in L1 production when participants were addressed in the target language (Experiment 1), while this effect disappeared when participants were addressed in the non-target language (Experiment 2). However, in both experiments, many observations had to be removed because participants were not able to name the L2 target translation (on average around $15 \%)$, thus reducing the power of the analyses. In Experiment 3, we therefore aimed to resolve the discrepancy between the findings from the two experiments by using an improved target-distractor set, in which the English names of the pictures were more likely to be known to the participants in English, thus minimising data loss. Furthermore, we restricted our investigation to SOA -150 ms because Experiment 1 had shown that the effect was strongest at this SOA. In Experiment 3, we returned to the "monolingual" language mode, i.e. as in Experiment 1, participants were again addressed in their L1 Dutch.

\section{Method}

\section{Participants}

Twenty-four students from the Radboud University Nijmegen (19 female, mean age: 22.1 years, $S D=2.8$ ) with normal hearing and normal or corrected-to-normal

Table 4. Mean naming latencies in ms and error rates in percent of Experiment 3, broken down by distractor condition.

\begin{tabular}{lcc}
\hline & $\mathrm{RT}$ in ms & error rates in \% \\
\hline translation-related & $709(16)$ & $6.8(1.5)$ \\
translation-unrelated & $670(11)$ & $3.8(0.7)$ \\
difference & 39 & 2.9 \\
cross-language phonologically related & $665(16)$ & $3.1(1.0)$ \\
cross-language phonologically unrelated & $665(12)$ & $4.2(1.3)$ \\
difference & 0 & -1.1 \\
\hline
\end{tabular}

Note. Difference $=$ related - unrelated in ms. Positive difference scores reflect interference from related distractors, and negative scores reflect facilitation from related distractors. Standard errors of the mean are given in brackets. vision participated in exchange for course credit or monetary reimbursement. All participants were native Dutch speakers and raised monolingually. Two participants were replaced because they knew less than two thirds of the target words in English. The 24 participants included in the analyses had an average of 9.9 years' experience of learning English $(S D=2.6)$.

\section{Materials, design, apparatus, \& procedure}

Experiment 3 was identical to Experiment 1, except for the following aspects. In order to reduce the number of missing observations, we excluded those items that were named with the correct English picture name by less than 75\% of participants in Experiments 1 and 2 and replaced them with items whose English names would presumably be more familiar to non-native speakers of English. This left us with 24 objects ( 21 from the previous item set and three new ones), which were again presented as black line drawings on a white screen, and for which four different distractors were created according to the criteria outlined in Experiment 1 (see Appendix B for a full list).

The design was identical to that of Experiment 1, except that we only tested one SOA (-150 ms). Accordingly, there was only one experimental block, reducing the length of an experimental session to about $35 \mathrm{~min}$.

\section{Results and discussion}

The data were analyzed as in Experiment 1. Again, items that were named correctly in English by less than $80 \%$ of the participants were removed from the phono-translation contrast (3 items; 144 trials; 6.3\%). These numbers show that we were successful in reducing data loss in Experiment 3 (see also the item scores in Table 2 above). 32 additional trials (1.5\%) in which the English translation was not produced by the participant were removed from the phono-translation conditions without coding an error, as were 44 trials (2.0\%) with naming latencies shorter than $200 \mathrm{~ms}$ or longer than 2000 ms. Additionally, 63 observations (2.9\%) were identified as outliers and removed from the analysis. 103 observations (4.8\%) were coded as erroneous and entered into the error analyses. Table 4 displays mean naming latencies and error rates broken down by distractor reference (phono-translation vs. phonological) and relatedness (related vs. unrelated), averaged across participants.

\section{Distractor effects in naming task}

In the phono-translation condition, related distractors increased naming latencies compared to the unrelated condition, although this effect statistically was only 
marginally significant $(\beta=18.56, S E=9.20, t=2.02, p$ $=.057)$. Descriptively, this pattern was also observed in the error rates, but was not reliable in the analysis ( $p$ $>$.141). In the cross-language phonological condition, there were no significant effects ( $p s>.526$ ).

\section{Influence of proficiency}

The lower part of Table 2 displays the results of the proficiency measures. Not surprisingly given the changed material set, participants knew significantly more translations than in Experiments $1(t(37.2)=2.203, p=.034)$ and $2(t(39.1)=2.448, p=.019)$. None of the other proficiency measures differed from those obtained in the previous experiments (all $p s>$.240). Furthermore, we again found no correlations between the distractor effect in the phono-translation condition and any of the proficiency measures (all $|r| s \leq .21$, uncorrected $p>.05$ ), suggesting that activation of the L2 translation is independent of individual proficiency. Including the proficiency measures in the linear mixed-effects models, however, yielded a significant interaction between the phono-translation effect and individual reading scores $(\beta=-1.07, \quad S E=0.49, \quad t=-2.17, \quad p=.033)$, hinting towards a larger phono-translation effect with lower reading comprehension abilities. However, since this is the only instance in which we found such a relationship, we will not put much emphasis on it. Separate experiments should explore whether this correlation indeed exists or was just a coincidental finding in the current study.

With respect to the main question, i.e. whether L2 translations are active during L1 production, Experiment 3 provided further evidence that this seems indeed to be the case. By using items which participants could name more consistently in English, we removed much of the data noise present in the previous experiments. This led to a phono-translation effect comparable to that obtained at SOA $-150 \mathrm{~ms}$ in Experiment 1, although in Experiment 3, the main effect of relatedness was not significant at the .05 level. However, an additional analysis combining the data from Experiments 1 (SOA $-150 \mathrm{~ms}$ only) and 3 yielded a significant main effect of relatedness $(\beta=20.19, S E=7.07, t=2.86, p=.008)$, but no interaction of relatedness and experiment $(p>.621)$, suggesting that the main effect of relatedness was indeed reliable for both experiments. In the next section, we will discuss further implications for bilingual language production.

\section{General discussion}

Previous research investigating the phono-translation effect found evidence that during L2 naming, the L1 translations of the target word are activated phonologically, reflecting an inability to suppress the dominant native language during naming in a foreign language. In three experiments, we investigated whether this also holds true in the opposite direction, i.e. whether naming in the dominant $L 1$ is susceptible to interference from the L2. We obtained evidence that this is indeed the case: When speakers had to name pictures in their L1 Dutch (e.g. "mes" [knife]), a distractor word phonologically related to the English (L2) translation (e.g. "knight") increased naming latencies compared to an unrelated distractor. This shows for the first time that even when speaking in one's dominant $L 1$, translations from the less dominant $L 2$ receive activation up to the phonological level. However, this phenomenon was restricted to situations in which participants were addressed in the target language (Dutch; Experiments 1 and 3). By contrast, when being addressed in the non-target language (English) throughout the experiment (Experiment 2), the phono-translation effect was not statistically reliable anymore, though descriptively still showing interference. This was unexpected, and at this point, we do not have an obvious explanation for this finding. It might be that boosting the non-target language through this bilingual context may have triggered increased language control, given that participants were aware that the naming had to be performed in L1. That is, participants may have inhibited the L2 more actively in this case in order to improve L1 naming performance, thus diminishing the influence of the distractor manipulation.

The phono-translation effect is conceptually different from phonological facilitation effects obtained from direct translation distractors. Between-language translation effects (e.g. producing "horse" in the presence of "paard", the Dutch translation for horse) are usually facilitatory and have been interpreted in terms of priming of the target utterance on both the conceptual and the lemma level. In contrast, phono-translation effects prime the target translation up to the phonological level, such that this naming alternative actively competes for selection in the present naming context and causes interference because it needs to be suppressed (Hermans et al., 1998; Costa et al., 2003). The present results are in line with this account, showing that this also works in the opposite direction.

A caveat of the current study - as well as of previous studies investigating the phono-translation effect (cf. Boukadi et al., 2015, Experiment 1) - is that the nontarget language was indirectly activated by the language of the distractors, i.e. we measured $\mathrm{L} 2$ activation during L1 production using L2 distractors. This indeed gives the non-target language an indirect boost. However, 
the fact that we obtained interference effects between the related and the unrelated condition (which both were L2 words) implies that the non-target L2 is indeed activated lexically. A more stringent test (both in the L1-L2 as well as the L2-L1) direction would of course be to either use distractors from the targetlanguage that are phonologically (un)related to the translation of the non-target language word. If related distractors then still yielded longer naming latencies compared to unrelated distractors, this would be strong support for target language non-selective lexical access in bilingual production. However, the difficulties we encountered with the cross-language phonological effect in the current study shows that cross-language phonological activation is difficult to obtain.

Across all three experiments, we found no influence of L2 proficiency on the size of the interference effect. However, in word recognition studies, an influence of $L 2$ proficiency on the degree of $L 2$ interference during $\mathrm{L} 1$ processing has indeed been reported. For instance, being highly immersed in an L2 environment has been associated with increased interference from L2 during L1 comprehension in a visual world task (Marian, Spivey, \& Hirsch, 2003; Spivey \& Marian, 1999). Furthermore, the cognate facilitation effect (i.e. faster reaction times to cognates compared to non-cognates) between $\mathrm{L} 1$ and $\mathrm{L} 3$ items has been shown to depend on L3 proficiency (van Hell \& Dijkstra, 2002). It should be noted, however, that in the present study, our participant samples were reasonably homogeneous in their L2 proficiency, i.e. English was indeed their second language, but according to their self-ratings (see Appendix $C$ for a summary), they were not highly immersed. The fact that we observed a phono-translation effect despite this relatively low immersion suggests that L2 co-activation during native language production is a rather stable phenomenon which cannot be suppressed even if the L2 is not part of the speaker's daily life. Future studies could investigate the influence of relative frequency of use and immersion on this effect. We would hypothesise that particularly highly immersed L2 speakers may exhibit larger interference effects while speakers who do not use the $L 2$ regularly still receive interference comparable to the one observed in the current study.

In conclusion, we show for the first time that the phono-translation effect, which previously had only been reported in L2 naming tasks, is also present in L1 naming. This shows that a speaker's L2 exerts a strong enough influence on L1 picture naming to differentially affect naming latencies by the co-activation of the L2 translation. This provides further support for an account of bilingual language production in which both languages compete for lexical selection.

\section{Note}

1. For all experiments, the experimenter was a native German speaker for whom English was the second and Dutch the third language.

\section{Disclosure Statement}

No potential conflict of interest was reported by the authors.

\section{Funding}

This work was supported by Deutsche Forschungsgemeinschaft [grant Number KL 2933/2].

\section{References}

Abutalebi, J., \& Green, D. W. (2007). Bilingual language production: The neurocognition of language representation and control. Journal of Neurolinguistics, 20(3), 242-275. http://doi.org/10.1016/j.jneuroling.2006.10.003

Baayen, R. H., Davidson, D. J., \& Bates, D. M. (2008). Mixed-effects modeling with crossed random effects for subjects and items. Journal of Memory and Language, 59(4), 390-412. http://doi.org/10.1016/j.jml.2007.12.005

Bates, D., Mächler, M., Bolker, B., \& Walker, S. (2015). Fitting linear mixed-effects models using Ime4. Journal of Statistical Software, 67(1), 1-48. http://doi.org/10.18637/jss. v067.i01

Boukadi, M., Davies, R., \& Wilson, M. A. (2015). Bilingual lexical selection as a dynamic process: Evidence from ArabicFrench bilinguals. Canadian Journal of Experimental Psychology, 69(4), 297-313. http://doi.org/10.1037/ cep0000063

Brysbaert, M., \& New, B. (2009). Moving beyond Kučera and Francis: A critical evaluation of current word frequency norms and the introduction of a new and improved word frequency measure for American English. Behavior Research Methods, 41(4), 977-990. http://doi.org/10.3758/BRM.41.4. 977

Colomé, À. (2001). Lexical activation in bilinguals' speech production: Language-specific or language-independent? Journal of Memory and Language, 45, 721-736. http://doi. org/10.1006

Costa, A. (2004). Speech production in bilinguals. In T. K. Bhatia \& W. C. Ritchie (Eds.), The handbook of bilingualism (pp. 201223). Oxford, UK: Blackwell Publishing Ltd. http://doi.org/10. 1002/9780470756997.ch8

Costa, A., Albareda, A., \& Santesteban, M. (2008). Assessing the presence of lexical competition across languages: Evidence from the stroop task. Bilingualism: Language and Cognition, 11(1), 121-131. http://doi.org/10.1017/S1366728907003252

Costa, A., \& Caramazza, A. (1999). Is lexical selection in bilingual speech production language-specific? Further evidence from Spanish-English and English-spanish bilinguals. Bilingualism: Language and Cognition, 2(3), 231-244.

Costa, A., Caramazza, A., \& Sebastián-Gallés, N. (2000). The cognate facilitation effect: Implications for models of lexical access. Journal of Experimental Psychology: Learning, Memory, and Cognition, 26(5), 1283-1296. http://doi.org/10. 1037/0278-7393.26.5.1283 
Costa, A., Colomé, À, Gómez, O., \& Sebastián-Gallés, N. (2003). Another look at cross-language competition in bilingual speech production: Lexical and phonological factors. Bilingualism: Language and Cognition, 6(3), 167-179. http:// doi.org/10.1017/S1366728903001111

Costa, A., Miozzo, M., \& Caramazza, A. (1999). Lexical selection in bilinguals: Do words in the bilingual's two lexicons compete for selection? Journal of Memory and Language, 41(3), 365397. http://doi.org/10.1006/jmla.1999.2651

Damian, M. F., \& Martin, R. C. (1999). Semantic and phonological codes interact in single word production. Journal of Experimental Psychology: Learning, Memory, and Cognition, 25, 1-18. http://doi.org/10.1037/0278-7393.25.2.345

De Bot, K. (1992). A bilingual production model: Levelt's "speaking" model adapted. Applied Linguistics, 13, 1-24.

de Groot, A. M. B., Borgwaldt, S., Bos, M., \& van den Eijnden, E. (2002). Lexical decision and word naming in bilinguals: Language effects and task effects. Journal of Memory and Language, 47(1), 91-124. http://doi.org/10.1006/jmla.2001.2840

Gollan, T. H., Forster, K. I., \& Frost, R. (1997). Translation priming with different scripts: Masked priming with cognates and noncognates in Hebrew-English bilinguals. Journal of Experimental Psychology. Learning, Memory, and Cognition, 23(5), 1122-1139. Retrieved from http://www.ncbi.nlm.nih. gov/pubmed/9293625

Green, D. W. (1998). Mental control of the bilingual lexicosemantic system. Bilingualism: Language and Cognition, 1, 67-81. http://doi.org/10.1017/S1366728998000133

Haigh, C. A., \& Jared, D. (2007). The activation of phonological representations by bilinguals while reading silently: Evidence from interlingual homophones. Journal of Experimental Psychology: Learning, Memory, and Cognition, 33(4), 623-644. http://doi.org/10.1037/0278-7393.33.4.623

Hermans, D. (2004). Between-language identity effects in picture-word interference tasks: A challenge for languagenonspecific or language-specific models of lexical access? International Journal of Bilingualism, 8(2), 115-125. Retrieved from http://journals.sagepub.com/doi/pdf/10. 1177/13670069040080020101

Hermans, D., Bongaerts, T., De Bot, K., \& Schreuder, R. (1998). Producing words in a foreign language: Can speakers prevent interference from their first language? Bilingualism: Language and Cognition, 1(3), 213-229. http://doi.org/10. 1017/S1366728998000364

Hermans, D., Ormel, E., van Besselaar, R., \& van Hell, J. G. (2011). Lexical activation in bilinguals' speech production is dynamic: How language ambiguous words can affect cross-language activation. Language and Cognitive Processes, 26(10), 1687-1709. http://doi.org/10.1080/ 01690965.2010 .530411

Jacobs, A., Fricke, M., \& Kroll, J. F. (2016). Cross-Language activation begins during speech planning and extends into second language speech. Language Learning, 66(2), 324353. http://doi.org/10.1111/lang.12148

Jaeger, T. F. (2008). Categorical data analysis: Away from ANOVAs (transformation or not) and towards logit mixed models. Journal of Memory and Language, 59(4). http://doi. org/10.1016/j.jml.2007.11.007

Keuleers, E., Brysbaert, M., \& New, B. (2010). SUBTLEX-NL: A new measure for Dutch word frequency based on film subtitles. Behavior Research Methods, 42(3), 643-650. http://doi.org/ 10.3758/BRM.42.3.643
Kroll, J. F., Bobb, S. C., Misra, M., \& Guo, T. (2008). Language selection in bilingual speech: Evidence for inhibitory processes. Acta Psychologica, 128(3), 416-430. http://doi.org/ 10.1016/j.actpsy.2008.02.001

Kroll, J. F., Bobb, S. C., \& Wodniecka, Z. (2006). Language selectivity is the exception, not the rule: Arguments against a fixed locus of language selection in bilingual speech. Bilingualism: Language and Cognition, 9(2), 119-135. http:// doi.org/10.1017/S1366728906002483

Kuznetsova, A., Bruckhoff, P. B., \& Christensen, R. H. B. (2016). ImerTest: Tests in linear mixed effects models. Retrieved from https://cran.r-project.org/package=ImerTest

Lemhöfer, K., \& Broersma, M. (2012). Introducing LexTALE: A quick and valid lexical test for advanced learners of English. Behavior Research Methods, 44(2), 325-343. http:// doi.org/10.3758/s13428-011-0146-0

Lemhöfer, K., Spalek, K., \& Schriefers, H. (2008). Cross-language effects of grammatical gender in bilingual word recognition and production. Journal of Memory and Language, 59(3), 312-330. http://doi.org/10.1016/J.JML.2008.06.005

Marian, V., Spivey, M., \& Hirsch, J. (2003). Shared and separate systems in bilingual language processing: Converging evidence from eyetracking and brain imaging. Brain and Language, 86, 70-82. http://doi.org/10.1016/S0093-934X(02)00535-7

Misra, M., Guo, T., Bobb, S. C., \& Kroll, J. F. (2012). When bilinguals choose a single word to speak: Electrophysiological evidence for inhibition of the native language. Journal of Memory and Language, 67(1), http://doi.org/10.1016/j.jml. 2012.05.001

Pallier, C., Colomé, À, \& Sebastián-Gallés, N. (2001). The influence of native-language phonology on lexical access. Psychological Science, 12(6), 445-449. http://doi.org/10. 1111/1467-9280.00383

R Core Team. (2017). R: A language and environment for statistical computing. Vienna, Austria: R Foundation for Statistical Computing. Retrieved from https://www.r-project.org

Schriefers, H., Meyer, A. S., \& Levelt, W. J. M. (1990). Exploring the time course of lexical access in language production: Pictureword interference studies. Journal of Memory and Language, 29(1), 86-102. http://doi.org/10.1016/0749-596X(90)90011-N

Spalek, K., Hoshino, N., Wu, Y. J., Damian, M. F., \& Thierry, G. (2014). Speaking two languages at once: Unconscious native word form access in second language production. Cognition, 133(1), 226-231. http://doi.org/10.1016/j.cognition.2014.06.016

Spivey, M. J., \& Marian, V. (1999). Cross talk between native and second languages: Partial activation of an irrelevant lexicon. Psychological Science, 10(3), 281-284. http://doi.org/10.1111/ 1467-9280.00151

Starreveld, P. A., de Groot, A. M. B., Rossmark, B. M. M., \& van Hell, J. G. (2014). Parallel language activation during word processing in bilinguals: Evidence from word production in sentence context. Bilingualism: Language and Cognition, 17 (2), 258-276. http://doi.org/10.1017/S1366728913000308

Strijkers, K., Costa, A., \& Thierry, G. (2010). Tracking lexical access in speech production: Electrophysiological correlates of word frequency and cognate effects. Cerebral Cortex, 20(4), 912-928. http://doi.org/10.1093/cercor/bhp153

van Hell, J. G., \& Dijkstra, T. (2002). Foreign language knowledge can influence native language performance in exclusively native contexts. Psychonomic Bulletin \& Review, 9(4), 780789. Retrieved from http://www.ncbi.nlm.nih.gov/pubmed/ 12613683 